\title{
Interferência de Plantas Daninhas na Cultura do Quiabo ${ }^{1}$
}

\author{
Weed Interference in Okra Crop
}

\author{
SANTOS, J.B. ${ }^{2}$, SILVEIRA, T.P. ${ }^{3}$, COELHO, P.S. ${ }^{3}$, COSTA, O.G. ${ }^{3}$, MATTA, P.M. ${ }^{4}$, SILVA, M.B. ${ }^{5}$ e \\ DRUMOND NETO, A.P. ${ }^{3}$
}

\begin{abstract}
RESUMO - Objetivou-se com este trabalho avaliar os periodos de interferência das plantas daninhas na cultura do quiabo (Abelmoschus esculentus) na região do Médio Vale do Rio Doce, em Minas Gerais. O experimento foi conduzido em campo, entre maio e outubro de 2007. Utilizaram-se sementes do quiabo Santa Cruz-47, semeadas no espaçamento de $0,25 \times 1 \mathrm{~m}$. Foram estabelecidos diferentes periodos de controle das plantas daninhas na cultura, variando entre zero e 120 dias após a emergência (DAE). Foram avaliados 12 tratamentos, correspondendo a diferentes periodos de controle das plantas daninhas na cultura: capina após a emergência a partir dos 20, 40, 60, 80 e 100 dias; capina após a emergência até os 20, 40, 60, 80 e 100 dias; além de duas testemunhas com capina, ou não capinadas, ambas por 120 dias. Determinou-se o número de frutos por planta e o rendimento (produtividade), bem como os valores em dias para periodo anterior à interferência (PAI), período crítico de prevenção da interferência (PCPI) e periodo total de prevenção da interferência (PTPI), considerando $5 \%$ de perdas. A partir das espécies encontradas na área experimental, avaliou-se também, em vasos, isoladamente ou em competição com o quiabeiro, a capacidade competitiva das principais plantas daninhas. Com base nos resultados, verificou-se que o PAI estimado foi de $25 \mathrm{DAE}$, indicando a época de início das capinas. Para o PCPI, o período observado foi de 75 dias, indicando PTPI de 100 DAE. Entre as plantas daninhas presentes, Eleusine indica apresentou maior capacidade competitiva sobre a cultura.
\end{abstract}

Palavras-chave: Abelmoschus esculentus, agricultura familiar, Médio Vale do Rio Doce.

\begin{abstract}
An experiment was carried out under field conditions in Médio Vale do Rio Doce-MG, from May to October, 2007, to establish periods of weed interference in Abelmoschus esculentus crop. 'Santa Cruz-47' seeds were sown in a $0.25 \times 1.0 \mathrm{~m}$ spacing, and weed control times varied from 0 to 120 days after emergence (DAE). Number of fruit per plant and yield as well as values in days for Period Previous to Interference (PPI), Critical Prevention Period of Interference (CPPI) and Total Period of Interference Prevention (TPIP) were determined, considering 5\% loss. Plants from the species studied were placed in the plots, isolated or in competition with A. esculentus, aiming to to evaluate the competitive capacity of the main weeds. Area, number of leaves and plant height of A. esculentus were evaluated. Yield and number of fruit presented a similar behavior. The estimated PPI was 25 days, indicating when to start weed control. The CPPIobserved was 75 days, indicating 100 days for TPIP. Among the weeds evaluated, Eleusine indica showed the highest competitive capacity against the the crop.
\end{abstract}

Keywords: Abelmoschus esculentus, family farming, Médio Vale do Rio Doce.

1 Recebido para publicação em 21.11.2009 e na forma revisada em 15.6.2010.

2 Professor do Dep. de Agronomia da Universidade Federal dos Vales do Jequitinhonha e Mucuri - DAG/UFVJM, DiamantinaMG, <jbarbosa@ufvjm.edu.br>; ${ }^{3}$ Discentes do curso de Agronomia da Universidade Vale do Rio Doce - UNIVALE, Governador Valadares-MG; ${ }^{4}$ Discente do curso de Agronomia da Universidade Federal Rural do Rio de Janeiro - UFRRJ, Seropédica-RJ, $<$ matta542@hotmail.com>; ${ }^{5}$ Professor Adjunto da Universidade Federal do Espírito Santo - UFES, São Mateus-ES, $<$ barretofito@uol.com.br>. 


\section{INTRODUÇÃO}

No Brasil, a cultura do quiabo (Abelmoschus esculentus) encontra condições excelentes para desenvolvimento, principalmente quanto aos fatores climáticos, com destaque para as regiões Nordeste e Sudeste. Considerando a realidade local, a Região do Médio Vale do Rio Doce, povoada intensamente a partir de 1930 em função da comunicação ferroviária com o litoral brasileiro, foi extremamente explorada para fins pecuários. Nesses locais, o cenário compreende exposição do solo e ocorrência generalizada de erosão em vários estádios, onerando tecnologias para implementação de práticas conservacionistas de caráter vegetativo, edáfico e/ou mecânico. Em meio a essa forma predominante de ocupação do setor agrícola, algumas comunidades que utilizam o sistema de agricultura familiar vêm promovendo formas diferenciadas de ocupação do solo.

A agricultura familiar local, apesar de ocupar apenas $20 \%$ da área total, emprega mais de $60 \%$ da mão de obra e $75 \%$ das propriedades (Florisbelo, 2005). Esses agricultores não têm a pecuária como única ou principal atividade, introduzindo sistemas diversificados da produção, com destaque para as culturas anuais de grãos, perenes, fruteiras e hortaliças. Esta última é bastante significativa, e o seu principal produto é o quiabo. No entanto, o cenário aponta que a grande quantidade de familias não recebe qualquer tipo de apoio técnico para o desenvolvimento dessas culturas (Florisbelo, 2005).

Considerando a fragilidade da agricultura na região, sobretudo no que se refere à cultura do quiabo, tornam-se fundamentais estudos fitotécnicos para a correta condução dessa cultura, visando oferecer aos agricultores técnicas mais acessiveis e menos onerosas, para que, associado ao aumento da produtividade, se obtenha maior lucro.

As plantas daninhas constituem um dos principais componentes bióticos do agroecossistema dessa cultura, sendo passiveis de interferência durante seu desenvolvimento, o que, consequentemente, pode refletir em baixa produtividade. Quando não manejadas adequadamente, as plantas daninhas interferem no processo produtivo, competindo pelos recursos do meio, principalmente água, luz e nutrientes, liberando compostos alelopáticos, atuando como hospedeiras de pragas e doenças e interferindo nas práticas de colheita (Pitelli, 1985). A competição se define a partir do momento em que o ambiente não consegue suprir as quantidades limitadas dos fatores essenciais ao crescimento normal de uma população qualquer de plantas (Silva et al., 2007a).

O quiabo possui algumas características desejáveis, como custo de produção economicamente viável, resistência a várias pragas e considerado valor alimentício e nutritivo (Mota et al., 2000). É normalmente cultivado em espaçamentos largos, sendo a emergência das plântulas e o crescimento inicial lentos, o que favorece o surgimento de plantas daninhas e, nesse caso, onera o custo de produção.

Em relação à competição por nutrientes, a nutrição mineral do quiabeiro caracterizase por uma extração de macro e micronutrientes lenta até os 20 dias, aumentando posteriormente (Costa et al., 1972). Esse estádio pode coincidir com o período em que a interferência negativa exercida pelas plantas daninhas se torna irreversivel. Normalmente, os métodos mecânicos de controle englobam capina manual, uso de cultivadores, enxadas ou sacho. Para outras culturas, os herbicidas têm sido utilizados com frequência, devido ao menor custo e fácil manuseio (Silva et al., 2007b). No caso particular do quiabo, não existem opções de controle além do trifluralin, que apresenta uma série de riscos ambientais, intervalo de segurança não determinado, além da necessidade de incorporação ao solo devido ao risco da fotodegradação (Grover et al., 1997; Rodrigues \& Almeida, 2005).

O manejo integrado de plantas daninhas (MIPD) inclui diversas práticas de controle, sendo as mais importantes aquelas ligadas ao controle cultural, ou seja, adotar uma série de estratégias para que a cultura vença a competição com as plantas daninhas, diminuindo os custos com a capina.

Objetivou-se com este estudo determinar os periodos de interferência das plantas daninhas na cultura do quiabeiro na região do Médio Vale do Rio Doce, além da capacidade competitiva dessa cultura e de sete plantas daninhas comuns em áreas de produção, na fase inicial de desenvolvimento. 


\section{MATERIAL E MÉTODOS}

O experimento foi realizado no campus da Universidade Vale do Rio Doce, em solo previamente caracterizado e corrigido segundo recomendações para a cultura do quiabo, no período entre maio e dezembro de 2007. Utilizaram-se sementes do quiabo Santa Cruz47 semeadas no espaçamento de $0,25 \times 1 \mathrm{~m}$. Foram avaliados 12 tratamentos, correspondendo a diferentes períodos de controle das plantas daninhas na cultura: capina após a emergência a partir dos 20, 40, 60, 80 e 100 DAE (dias após a emergência); capina após a emergência até os 20,40,60, 80 e 100 DAE; além de duas testemunhas com capina, ou não capinadas, ambas por $120 \mathrm{DAE}$.

Após o início do período de colheita, a cada três dias foram coletados todos os frutos comerciais das plantas, segundo classificação proposta por Silva (2001). Os frutos não comerciais foram descartados. Por ocasião do início do florescimento da cultura, foram avaliadas as variáveis: diâmetro de caule, área foliar, massas secas de folhas, raízes e caule, altura e número de folhas por plantas, além da relação entre parte aérea e raízes. Aos $120 \mathrm{DAE}$ foram determinados o número total de frutos por planta e o rendimento (produtividade), bem como os valores em dias para período anterior à interferência (PAI), período crítico de prevenção da interferência (PCPI) e período total de prevenção da interferência (PTPI), segundo Pitelli (1985), considerando 5\% de perdas.

Para avaliação da capacidade competitiva, outro experimento foi montado em casa de vegetacão, em vasos contendo solo classificado como Argissolo Vermelho-Amarelo. A partir de critérios de importância sociológica (frequência, abundância e densidade), foram selecionadas sete espécies de plantas daninhas (Alternanthera tenela, Arachis pintoe, Bidens pilosa, Commelina benghalensis, Cyperus rothundus, Eleusine indica e Ipomoea nil), sendo semeadas nos vasos, isoladamente ou em competição com o quiabo (Abelmoschus esculentus). Dessa forma, foram estabelecidos 15 tratamentos, sendo o último o quiabo isoladamente. Foram semeadas 15 sementes das plantas daninhas ou seis da cultura. Após desbaste das plântulas, estabeleceram-se duas plantas por espécie em cada vaso. Aos 50 dias após a semeadura (DAS), todas as plantas foram colhidas e foi quantificada a massa seca da parte aérea (MSPA). Para o quiabeiro, também foram avaliadas a área foliar e o número de folhas, além da altura de plantas. Para determinação da MSPA, as plantas foram cortadas rente ao solo e secas em estufa a $75{ }^{\circ} \mathrm{C}$ por 72 horas, seguida pela pesagem em balança de precisão. Estabeleceu-se o ranqueamento das plantas daninhas avaliadas quanto à produção relativa de massa seca.

Os dados foram avaliados separadamente dentro de cada grupo (períodos iniciais de convivência ou de controle das plantas daninhas) e submetidos à análise de variância, pelo teste $\mathrm{F}$ a $5 \%$ de probabilidade, e de regressão pelo modelo sigmoidal de Boltzmann, conforme utilizado por Kuva et al. (2000):

$$
Y=\frac{(P 1-P 2)}{1+e^{\left(X-X_{0}\right) / d x}}+P 2
$$

em que: $Y=$ produtividade de frutos em função dos períodos de controle ou convivência; $X=$ limite superior do período de controle ou convivência (dias); $P 1=$ produtividade máxima obtida no tratamento mantido no limpo durante todo o ciclo; $P 2$ = produtividade mínima obtida no tratamento mantido em convivência com as plantas daninhas durante todo o ciclo; $X_{0}=$ limite superior do período de controle ou convivência, que corresponde ao valor intermediário entre a produtividade máxima e a mínima; e $\mathrm{dx}=$ velocidade de perda ou ganho de produtividade (tangente no ponto $X_{0}$ ). Na determinação dos coeficientes do modelo pela análise de regressão, o grau de ajuste foi avaliado pelo coeficiente de determinação, e a verificação da significância dos coeficientes, pelo teste t de Student a 5\% de probabilidade.

Os limites dos períodos de interferência (PAI, PTPI e PCPI) foram determinados tolerando-se perdas máximas de produtividade de frutos para o nivel arbitrário de 5\%, em relação ao tratamento mantido no limpo durante todo o ciclo.

Para o ensaio de competição, as médias foram submetidas à análise de variância e, quando significativas, comparadas pelo teste de Duncan a $5 \%$ de probabilidade. 


\section{RESULTADOS E DISCUSSÃO}

A mato-interferência proporcionou queda no número e, consequentemente, na produtividade de frutos de quiabo - fato que pode ser observado nas Figuras 1 e 2, que relacionam, respectivamente, o número e a produção de frutos com os períodos de capina.

Apesar de o modelo sigmoidal de Boltzmann também se adequar à relação de comportamento entre número de frutos de quiabo e períodos de controle das plantas daninhas, observou-se curva menos acentuada para essa variável, ou seja, tendência à linearidade (Figura 1).

O decréscimo observado na produção do número de frutos de quiabo em função dos dias de convivência entre a cultura e as plantas daninhas ou dias sem controle repercutiu na produtividade final, com comportamento semelhante (Figura 2). Percebe-se na evolução dos dias de convivência, entre cultura e plantas daninhas, considerado efeito negativo da presença destas sobre aquela cultura a partir dos 25 dias. Em vários estudos relacionando evolução da competição entre culturas e plantas daninhas, os resultados têm apontado 20 a 30 dias como época coerente para início da capina, conforme foi verificado para a soja por Spadotto et al. (1994); para o feijão, por Kozlowski et al. (2002); para o milho, por Kozlowski (2002); para girassol, por Briguenti et al. (2004); e para batata, por Costa et al. (2008).

Observando os períodos de convivência entre plantas daninhas e cultura, percebe-se a tendência de três fases distintas: decréscimo inicial lento no número de frutos produzidos no período de 25 dias iniciais de convivência; queda exponencial (pronunciada) no referido indice entre 25 e 80 dias; e tendência para estabilização de baixo número de frutos e produtividade a partir de 80 dias de convivência (Figuras 1 e 2).

Considerando $5 \%$ de perdas, ou seja, quando a convivência entre cultura e plantas daninhas passa a provocar diminuição na produtividade de frutos comerciais dessa magnitude nas plantas de quiabo (comparadas à testemunha livre da competição), foi estimado como período anterior à interferência (PAI)

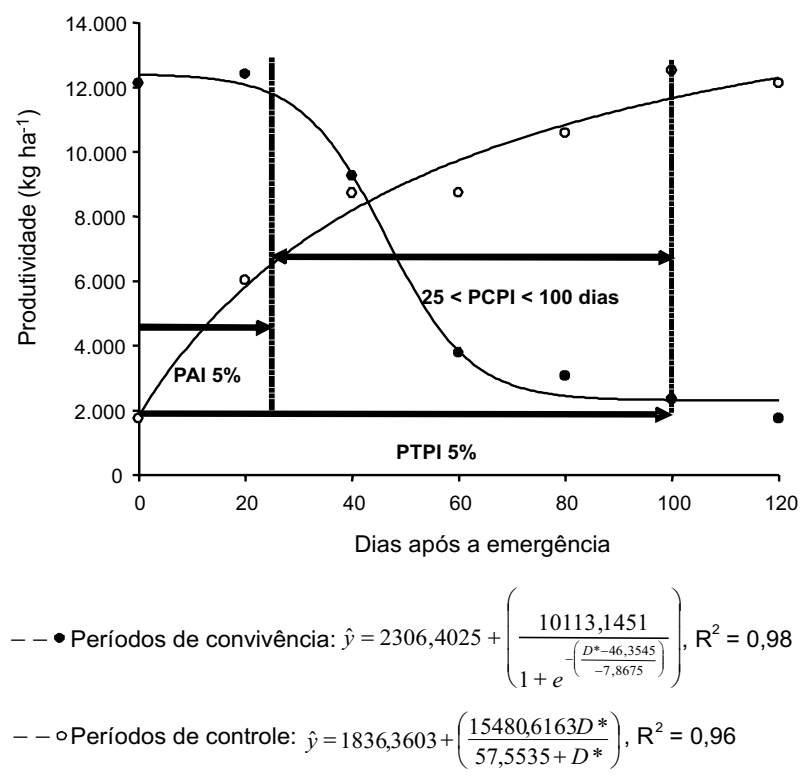

Figura 1 - Estimativa do número de frutos de quiabo por planta em função do manejo com controle e com convivência das plantas daninhas. $\left.\mathrm{D}=\mathrm{DAE} ;{ }^{*}\right)=$ significativo a $5 \%$ pelo teste $\mathrm{t}$ de Student. Linhas tracejadas na vertical indicam limitações para o período anterior (0-25 dias), crítico (25-100 dias) e total de prevenção da interferência (0-100 dias), respectivamente PAI, PCPI e PTPI, considerando 5\% de perda aceitável.

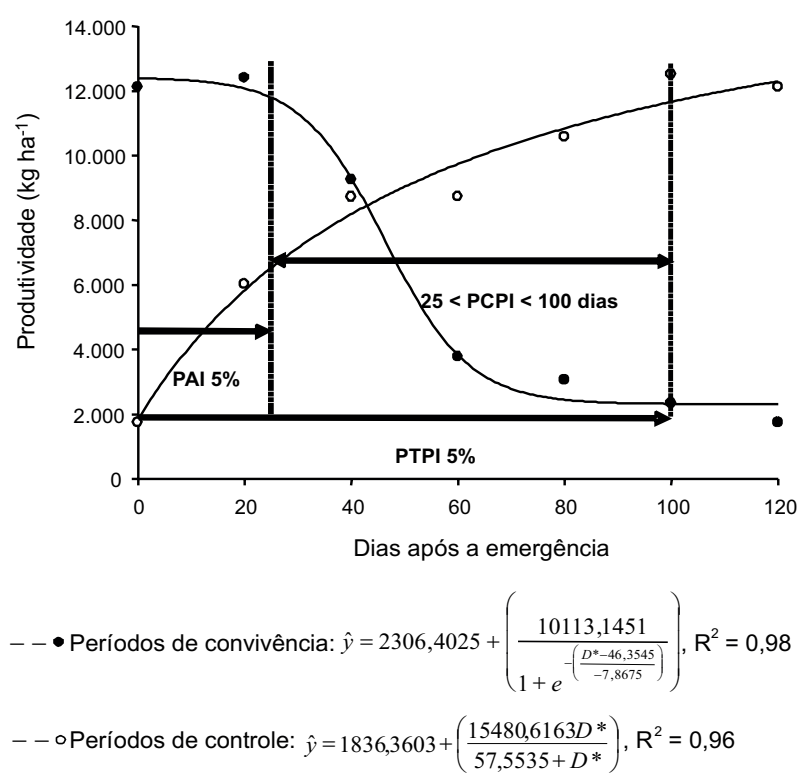

Figura 2 - Estimativa da produtividade de frutos comerciais de quiabo em função do manejo com controle e com convivência das plantas daninhas. $\mathrm{D}=\mathrm{DAE} ;\left(^{*}\right)=$ significativo a $5 \%$ pelo teste $t$ de Student. Linhas tracejadas na vertical indicam limitações para o período anterior (0-25 dias), crítico (25-100 dias) e total de prevenção da interferência (0-100 dias), respectivamente PAI, PCPI e PTPI, considerando $5 \%$ de perda aceitável. 
$25 \mathrm{DAE}$, indicando a época de início das capinas. A partir da observação de mercado, conforme variação do preço médio do quiabo, se o produtor optar pelo controle admitindo-se perda de $10 \%$, o PAI e o período crítico de prevenção da interferência (PCPI) alteram, respectivamente, para 31 e $54 \mathrm{DAE}$, representando economia de 21 dias sem capina. Nesse caso, o período total da prevenção da interferência (PTPI) observado será de 85 DAE (Figura 2). Essa constatação baseia-se na teoria do Periodo Anterior ao Dano no Rendimento Econômico (PADRE), estabelecido por Vidal et al. (2005). Segundo esses autores, aspectos econômicos, como o custo de controle e o valor monetário dos produtos colhidos, devem ser utilizados como critério estabelecido para determinar o período aceitável de interferência das plantas daninhas antes de se decidir pelo seu controle.

Na prática, várias das etapas para a correta condução da cultura do quiabo incluem emprego de insumos e mão de obra disponíveis na propriedade agrícola como "resíduos" ou integrados a outras atividades. Segundo Baiardi (2007), essa diversificação e o uso integrado de recursos e mão de obra são, principalmente, notados na agricultura classificada como "familiar", em que a sustentabilidade obtida na divisão familiar do trabalho e a integração dos métodos para produção (incluindo injeção de adubos produzidos no próprio local, controle cultural de pragas, doenças e plantas daninhas e rotação de culturas) diminuem consideravelmente os custos individuais para cálculo da rentabilidade final.

Foram realizadas avaliações de massa seca e área foliar na tentativa de esclarecer melhor os resultados observados para queda na produtividade com a evolução dos períodos de competição entre cultura e plantas daninhas (Tabela 1). A massa seca das folhas em plantas de quiabo apresentou considerada variação em função da interferência, sendo o valor dessa característica $68 \%$ menor nas parcelas sob interferência das plantas daninhas por 40 dias. Na prática, plantas de quiabo não capinadas por 40 dias produziram área foliar correspondente a $32 \%$ daquela observada nas plantas capinadas por todo o período.

Observou-se que a diminuição acentuada na massa seca de folhas do quiabeiro foi consequência da menor produção de número de folhas observada aos 40 dias de competição. Para as demais características avaliadas, as capinas durante todo o período ou realizadas aos 20 DAE não apresentaram diferenças. Em outro trabalho, a presença de plantas daninhas, destacando-se Cyperus rotundus, promoveu redução de $65 \%$ na produtividade do quiabeiro, a qual foi atribuída à elevada competitividade pelos nutrientes disponíveis no solo (William \& Warrem, 1975). Outra possibilidade é a interferência das plantas daninhas na competição entre frutos e folhas pelos fotoassimilados. Sabe-se que, na cultura do quiabo, o ponto de colheita dos frutos é determinado pela maturidade hortícola, isto é, quando a quantidade de fibras nos frutos não excede $6,5 \%$. Nesse estádio, os frutos ainda não atingiram completo crescimento e desenvolvimento, sendo eficientes drenos enquanto tenros (Duzyaman, 1997), competindo, dessa forma, também para menor produção de parte aérea ou raízes.

Tabela 1 - Características avaliadas em plantas de quiabo (Abelmoschus esculentus) por ocasião do florescimento, em função da competição com plantas daninhas ou livres da interferência

\begin{tabular}{|l|c|c|c|c|c|c|c|c|}
\hline \multicolumn{1}{|c|}{ Tratamento } & $\begin{array}{c}\text { Diâmetro } \\
\text { de caule } \\
(\mathrm{mm})\end{array}$ & $\begin{array}{c}\text { Área foliar } \\
\left(\mathrm{cm}^{2}\right)\end{array}$ & $\begin{array}{c}\text { MSF } \\
(\mathrm{g})\end{array}$ & $\begin{array}{c}\text { MSR } \\
(\mathrm{g})\end{array}$ & $\begin{array}{c}\text { MSC } \\
(\mathrm{g})\end{array}$ & $\begin{array}{c}\text { Altura } \\
(\mathrm{cm})\end{array}$ & $\begin{array}{c}\text { Número de } \\
\text { folhas }\end{array}$ & \begin{tabular}{c} 
RPAR \\
\hline Sem interferência
\end{tabular} \\
\hline Interferência por 20 dias & $10,91 \mathrm{a}$ & $98,54 \mathrm{a}$ & $12,58 \mathrm{a}$ & $4,65 \mathrm{a}$ & $10,8 \mathrm{a}$ & $30,35 \mathrm{a}$ & $31,00 \mathrm{a}$ & $5,06 \mathrm{a}$ \\
\hline Interferência por 40 dias & $8,4 \mathrm{a}$ & $78,24 \mathrm{a}$ & $12,32 \mathrm{a}$ & $4,04 \mathrm{a}$ & $8,32 \mathrm{a}$ & $30,30 \mathrm{a}$ & $41,25 \mathrm{a}$ & $5,13 \mathrm{a}$ \\
\hline \multicolumn{1}{|c|}{ CV (\%) } & 22,0 & 12,73 & 13,76 & 12,99 & 16,33 & 11,02 & 9,99 & 18,34 \\
\hline
\end{tabular}

Médias seguidas por letras iguais em cada coluna não diferem entre si pelo teste de Duncan a 5\% de probabilidade. MSF: massa seca de folhas; MSR: massa seca de raízes; RPAR: relação entre parte aérea e raízes. 
Entre as espécies de plantas daninhas presentes na área experimental, destacaramse Alternanthera tenella, Arachis pintoe, Bidens pilosa, Commelina benghalensis, Cyperus rotundus, Eleusine indica e Ipomoea nil, posteriormente cultivadas em vasos em competição com plantas de quiabo (Tabela 2). A partir desse ensaio, observou-se, para a cultura, que a massa seca da parte aérea foi severamente afetada pelas espécies, com destaque para E. indica. A produção de área foliar somente foi semelhante à da testemunha quando o quiabeiro foi cultivado junto a $A$. pintoe, indicando ser esta uma possivel leguminosa a ser implementada em consórcio com essa cultura. É amplamente aceito o aspecto positivo do consórcio entre hortaliças, principalmente na contribuição para a proteção do solo, melhor distribuição temporal da renda dos agricultores, além do melhor controle de plantas daninhas (Oliveira et al., 2005; Guedes et al., 2006).

O número de folhas produzido pelas plantas de quiabo também foi negativamente alterado quando a cultura se desenvolveu em competição $\operatorname{com} E$. indica. Mesmo sabendo da variação na capacidade competitiva das plantas entre variedades de quiabo (Mota et al., 2008), são sempre verificadas em campo infestações significativas de gramíneas, em razão de sua ocorrência em ambientes favoráveis ao desenvolvimento do quiabeiro.
Considerando a capacidade competitiva do quiabeiro sobre cada planta daninha avaliada, $B$. pilosa e $I$. nil foram as mais afetadas negativamente, apresentando, quando em competição, menos de $41 \%$ da MSPA observada nos vasos sem interferência da cultura. E. indica foi a única planta daninha não afetada negativamente pela presença do quiabeiro (Tabela 3 e Figura 3). Esses resultados expõem a capacidade competitiva diferencial entre culturas e plantas daninhas, muitas vezes sem importância nos estudos para análise de crescimento vegetal. Nos cultivos agricolas, geralmente a cultura tem a população de indivíduos controlada, enquanto a população das espécies consideradas daninhas varia em função de diversos fatores, incluindo quantidade de sementes depositadas no banco do solo, nível de infestação e condições encontradas no local. Assim, além da avaliação da população de plantas no processo competitivo, deve-se atentar para a influência da variação na proporção entre espécies (Christoffoleti \& Victoria Filho, 1996).

Nesse sentido, a competição observada entre a cultura do quiabo e $B$. pilosa é bem menos prejudicial, se comparada à competição com E. indica. Credita-se às condições climáticas o maior favorecimento dessa graminea na supressão do quiabeiro, comparada às demais espécies, dado seu metabolismo tipo $\mathrm{C}_{4}$, cujo desenvolvimento é favorecido pelas

Tabela 2 - Características avaliadas para o quiabeiro (Abelmoschus esculentus), no início do estádio de florescimento, cultivado em vasos competindo com diferentes plantas daninhas por 50 dias

\begin{tabular}{|l|c|c|c|c|}
\hline \multicolumn{1}{|c|}{ Espécie competidora } & $\begin{array}{c}\text { MSPA }^{1 /} \\
(\mathrm{g})\end{array}$ & $\begin{array}{c}\text { Área foliar } \\
\left(\mathrm{cm}^{2}\right)\end{array}$ & Número de folhas & $\begin{array}{c}\text { Altura de plantas } \\
(\mathrm{cm})\end{array}$ \\
\hline Alternanthera tenella & $7,41 \mathrm{c}$ & $96,39 \mathrm{~b}$ & $7,54 \mathrm{a}$ & $17,38 \mathrm{a}$ \\
\hline Arachis pintoe & $18,03 \mathrm{a}$ & $159,63 \mathrm{a}$ & $8,75 \mathrm{a}$ & $20,42 \mathrm{a}$ \\
\hline Bidens pilosa & $9,17 \mathrm{bc}$ & $97,07 \mathrm{~b}$ & $7,83 \mathrm{a}$ & $17,04 \mathrm{a}$ \\
\hline Commelina benghalensis & $8,43 \mathrm{c}$ & $77,60 \mathrm{bc}$ & $6,38 \mathrm{a}$ & $14,50 \mathrm{a}$ \\
\hline Cyperus rotundus & $13,79 \mathrm{~b}$ & $67,01 \mathrm{bc}$ & $8,33 \mathrm{a}$ & $21,46 \mathrm{a}$ \\
\hline Eleusine indica & $1,25 \mathrm{~d}$ & $103,70 \mathrm{~b}$ & $4,67 \mathrm{~b}$ & $12,42 \mathrm{a}$ \\
\hline Ipomoea nil & $11,63 \mathrm{~b}$ & $24,38 \mathrm{c}$ & $8,25 \mathrm{a}$ & $18,54 \mathrm{a}$ \\
\hline Testemunha* & $18,34 \mathrm{a}$ & $136,68 \mathrm{a}$ & $8,92 \mathrm{a}$ & $21,87 \mathrm{a}$ \\
\hline \multicolumn{1}{|c|}{ CV $(\%)$} & 8,66 & 6,79 & 11,15 & 15,67 \\
\hline
\end{tabular}

1/ MSPA: massa seca da parte aérea; *'Quiabo sem competição. Médias seguidas por letras iguais em cada coluna não diferem entre si pelo teste de Duncan a $5 \%$ de probabilidade. 
Tabela 3 - Massa seca da parte aérea de plantas daninhas 50 dias após a emergência, cultivadas em vasos com e sem a interferência do quiabeiro (Abelmoschus esculentus)

\begin{tabular}{|l|c|c|}
\hline \multirow{2}{*}{ Espécie competidora } & \multicolumn{2}{|c|}{ Massa seca da parte aérea (g) } \\
\cline { 2 - 3 } & $\begin{array}{c}\text { Sem } \\
\text { competição }{ }^{-1}\end{array}$ & $\begin{array}{c}\text { Com } \\
\text { competição }^{\underline{1}}\end{array}$ \\
\hline Alternanthera tenela & $23,75 \mathrm{a}$ & $18,25 \mathrm{~b}$ \\
\hline Arachis pintoe & $3,93 \mathrm{a}$ & $1,93 \mathrm{~b}$ \\
\hline Bidens pilosa & $11,53 \mathrm{a}$ & $4,67 \mathrm{~b}$ \\
\hline Commelina benghalensis & $21,96 \mathrm{a}$ & $16,50 \mathrm{~b}$ \\
\hline Cyperus rothundus & $5,26 \mathrm{a}$ & $2,78 \mathrm{~b}$ \\
\hline Eleusine indica & $52,16 \mathrm{a}$ & $51,83 \mathrm{a}$ \\
\hline Ipomoea nil & $16,69 \mathrm{a}$ & $5,11 \mathrm{~b}$ \\
\hline \multicolumn{1}{|c|}{$\mathrm{CV}(\%)$} & $12,74 \mathrm{a}$ & $10,55 \mathrm{~b}$ \\
\hline
\end{tabular}

${ }^{1 /}$ Sem ou com a competição, em vasos, de plantas de Abelmoschus esculentus. Médias seguidas por letras iguais em cada linha não diferem entre si pelo teste $\mathrm{F}$ a $5 \%$ de probabilidade de erro.

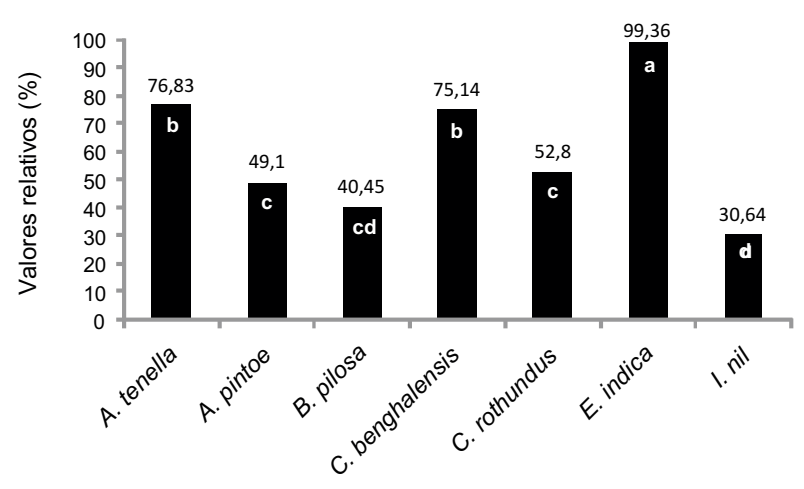

Figura 3 - Produção relativa de massa seca de parte aérea de diversas plantas daninhas quando em competição com quiabeiro (Abelmoschus esculentus) por 50 dias após a emergência. Médias seguidas por letras iguais não diferem entre si pelo teste de Duncan a 5\% de probabilidade, com CV de $11,89 \%$.

condições locais e por ocasião do trabalho (elevada insolação e temperatura média, associada à irrigação).

Comparando a produção relativa de massa seca entre todas as espécies de plantas daninhas avaliadas, observa-se a seguinte escala de tolerância à competitividade exercida pelo quiabeiro: $E$. indica $>A$. tenella $=$ $C$. benghalensis $>C$. rotundus $=A$. pintoe $=$ B. pilosa $\geq$ I. nil (Figura 3). A produção relativa fornece uma ideia do comportamento individual das espécies no processo competitivo. Para vários autores, o maior conhecimento dos processos competitivos relacionados ao consórcio ou à competição entre cultura e comunidade de plantas daninhas é o único caminho viável para se incrementar a interação positiva entre as culturas envolvidas dentro de um sistema de produção integralizado (Jones Jr. \& Walker, 1993; Castro \& Garcia, 1996).

Pode-se concluir que $25 \mathrm{DAE}$ do quiabo indica o início da competição das plantas daninhas com essa cultura. Esse intervalo se prolonga até os $100 \mathrm{DAE}$, quando plântulas emergidas não mais competem significativamente com a cultura. Entre as espécies infestantes, E. indica apresentou maior capacidade competitiva sobre as plantas de quiabo, e a leguminosa $A$. pintoe destacou-se como alternativa para utilização em consórcio com a cultura do quiabo.

\section{AGRADECIMENTOS}

À FAPEMIG e ao CNPq, pelo apoio financeiro à realização desta pesquisa.

\section{LITERATURA CITADA}

BAIARDI, A. Natureza e formas da agricultura familiar no Brasil e sua propensão a cooperar em projetos de desenvolvimento rural sustentável. In: SEMINÁRIO COMEMORATIVO DOS 30 ANOS DO CPDA/UFRRJ, 2007, Rio de Janeiro. Anais... Rio de Janeiro: CPDA/UFRRJ, 2007. v. 1. p. $127-146$.

BRIGHENTI, A. M. et al. Períodos de interferência de plantas daninhas na cultura do girassol. Planta Daninha, v. 22 , n. 2 , p. $251-257,2004$

CASTRO, C. R. T.; GARCIA, R. Competição entre plantas com ênfase no recurso luz. Ci. Rural, v. 26, n. 1, p. 167-174, 1996.

CHRISTOFFOLETI, P. J.; VICTORIA FILHO, R. Efeitos da densidade e proporção de plantas de milho (Zea mays L.) e caruru (Amaranthus retroflexus L.) em competição. Planta Daninha, v. 14, n. 1, p. 42-47, 1996

COSTA, M. C. B.; HAAG, H. P.; SARRUGE, J. R. Nutrição mineral de hortaliças. XIX. Absorção de macro e micronutrientes pela cultura do quiabeiro (Hibiscus esculentum L.). In: REUNIÃO DA SOCIEDADE BRASILEIRA DE HORTICULTURA, 29., 1972, Piracicaba. Anais... Piracicaba: ESALQ, 1972. p. 109-125.

COSTA, N. V. et al. Períodos de interferência de uma comunidade de plantas daninhas na cultura da batata. Planta Daninha, v. 26, n. 1, p. 83-91, 2008. 
DUZYAMAN, E. Okra: botany and horticulture. In: JANICK, J. Horticultural reviews. [S.1.: s.n.], 1997. p. 41-72.

FLORISBELO, G. R. Território do Médio Rio Doce Minas Gerais. Estudo propositivo da base econômica territorial. Ministério do Desenvolvimento Agrário. Secretaria de Desenvolvimento Territorial, 2005. 131 p. Disponível em: $<$ http://serv-sdt-1.mda.gov.br/gnc/gnc/ep/estudos/ MG_MedioRioDoce.pdf>. Acesso em: 16 set. 2007.

GROVER, R. et al. Environmental fate of trifluralin. Rev. Environ. Contam. Toxicol., v. 153, n. 1, p. 1-64, 1997.

GUEDES, R. E. et al. Produtividade do quiabeiro e do feijão-caupi consorciados em sistema orgânico de produção após cultivo de crotalária ou pousio. Disponível em: <http://www.cpamn.embrapa.br/ anaisconac2006/resumos/FT03.pdf $>$. Acesso em: 14 jan 2009.

JONES JR., R. E.; WALKER, R. H. Effect of interespecific interference, light intensity and soil moisture on soybean (Glycine max), common cocklebur (Xanthium strumarium) and sicklepod (Cassia obtusifolia) water uptake. Weed Sci., v. 41, n. 4, p. 534-540, 1993

KOZLOWSKI, L. A. et al. Interferência de plantas daninhas na cultura do feijoeiro comum em sistema de semeadura direta Planta Daninha, v. 20, n. 2, p. 213-220, 2002.

KOZLOWSKI, L. A. Período crítico de interferência das plantas daninhas na cultura do milho baseado na fenologia da cultura. Planta Daninha, v. 20, n. 3, p. 365-372, 2002.

KUVA, M. A. et al. Períodos de interferência das plantas daninhas na cultura da cana-de-açúcar. I - Tiririca. Planta Daninha, v. 18 , n. 2, p. 245-251, 2000.

MOTA, W. F. et al. Composição mineral de frutos de quatro cultivares de quiabeiro. Ci. Agrotec., v. 32, n. 3, p. 762-767, 2008 .
MOTA, W. F.; FINGER, F. L.; CASALI, V. W. D.

Olericultura: melhoramento genético do quiabeiro. Viçosa, MG: Universidade Federal de Viçosa, 2000. 144 p.

OLIVEIRA, F. L. et al. Desempenho do consórcio entre repolho e rabanete com pré-cultivo de crotalária, sob manejo orgânico. Hortic. Bras., v. 23, n. 2, p. 184-188, 2005.

PITELLI, R. H. Interferência de plantas daninhas em culturas agrícolas. Inf. Agropec., v. 11, n. 1, p. 16-27, 1985.

RODRIGUES, B. N.; ALMEIDA, F. S. Guia de herbicidas. 5.ed. Londrina: Grafmarke, 2005. 591 p.

SILVA, A. A. et al. Biologia de plantas daninhas. In.: SILVA, A. A.; SILVA, J. F.; (Eds.). Tópicos em manejo de plantas daninhas. Viçosa, MG: Universidade Federal de Viçosa, 2007a. 367 p

SILVA, A.A. et al. Métodos de controle de plantas daninhas. In: Tópicos em manejo de plantas daninhas. (Eds.) SILVA, A.A.; SILVA, J.F. Viçosa, MG: Universidade Federal de Viçosa, 2007b. 367 p.

SILVA, A. C. Programa Brasileiro para a Melhoria dos Padrões Comerciais e Embalagens de Hortigranjeiros Classificação do quaibo. Cartilha CEAGESP, 2001.

Disponível em: <www.ceagesp.gov.br/produtor/tecnicas/ classific/fc_quiabo>. Acesso em: 10 ago. 2009.

SPADOTTO, C. A. et al. Determinação do período crítico para prevenção da interferência de plantas daninhas na cultura da soja: uso do modelo "broken-stick". Planta Daninha, v. 12, n. 2 , p. $59-62,1994$.

VIDAL, R. A.; FLECK, N. G.; MEROTTO J. R. A. Período anterior ao dano no rendimento econômico (PADRE): nova abordagem sobre os períodos de interferência entre plantas daninhas e cultivadas. Planta Daninha, v. 23, n. 3, p. 387-396, 2005.

WILLIAM, R. D.; WARREM, G. F. Competition between purple nutsedge and vegetables. Weed Sci., v. 23, n. 4, p. 317-323, 1975. 